BIORHEOLOGY, 27; 265-268, 1990

$0006-355 \times / 90 \$ 3.00+.00$ Printed in the USA.

Copyright (c) 1990 Pergamon Press plc. All rights reserved.

PROCEEDINGS - PART I

SEVENTH INTERNATIONAL CONGRESS OF BIORHEOLOGY

NANCY, FRANCE, 18-23 JUNE 1989

\title{
WELCOME ADDRESS
}

J. F. Stoltz

President, The International society of Biorheology President, The International Congress of Biorheology

It is an honor for me to open today the seventh International congress of the International society of Biorheology.

I should like to thank all participants and, in particular, those who will present Papers or participate in symposia. It would not be possible to mention them all, for fear of forgetting some. However, I hope that you will allow me to make two exceptions: one for A.L. Copley, whom I have the pleasure of welcoming today to Nancy for the fifth time, and one for R. Skalak, who, shortly after this opening Ceremony will be the Ninth Awardee of the Poiseuille Gold Medal.

I also wish to thank the regional and local authorities present today at this Inaugural session. They have at all times supported the biomedical research undertaken in the laboratories of our universities. I should also not forget those representatives of industry, who participate in the exhibits or who have given us financial support. 
Finally, I wish to thank the members of the scientific Committee and, in particular, M. Donner, who have helped me in the organization and preparation of the scientific Program of our Conference.

1989 is a twin anniversary, not only the Bicentenary of the French Revolution, but also the Twentieth Anniversary of our society, originally named The International society of Hemorheology. It was created in Reykjavik in 1966, initiated by our friend A.L. Copley. The second conference was held in Heidelberg in 1969. Our present congress should in fact have the number 9. It is a source of a certain emotion to me to mention this First International conference on Hemorheology, which I attended as a young researcher. I believe that all of those who were present still have the memory of an exceptional meeting. Some have now left us, such as R. Fåhræus, S.G. Mason, G.W. Scott-Blair, but their presence continues due to their pioneering work.

Following Lyon (1972), Rehovot (1975), La Jolla (1978), Tokyo (1981), Baden-Baden (1983) and Vancouver (1986), this VII. Congress represents a turning point in the life of our Society. From approximately 100 persons who came to Reykjavik from some 12 countries, we are now here more than 550 colleagues with 25 countries represented. It is a pleasure for me to welcome in large numbers new scientific communities concerned with biorheology, such as our colleagues from china or from India.

1989 marks also the Tenth Anniversary of the First European Conference on Clinical Hemorheology, organized with my colleague and friend $P$. Drouin and held here in Nancy in October 1979. It fulfilled for us the need to link hemorheology with clinical research. The 6 th conference has 
just been held last week in Frankfurt with A.M. Ehrly as its President.

The Program of this congress is crowded, perhaps overcrowded. However, we wished this congress to be a bridge between theory and methodology, as well as a bridge between clinical and pharmacological aspects. The Scientific committee has received more than 500 papers and accepted a little more than 400. We hope they will offer a comprehensive account of the range of different applications of biorheology in the life sciences, since, as A.L.Copley stressed in BIORHEOLOGY in his Plenary Lecture, entitled 'The future of the science of Biorheology' (Biorheology 19, 47-69, 1982) that biorheology must be considered as "the missing link in most life sciences".

The Communications, which will be presented during these five days, are divided into 24 symposia, 24 Free Communication Sessions and 3 Poster sessions with 63 Posters.

In addition to this Scientific Program, I should like to welcome you to Nancy, a university city and tourist centre of Lorraine, which boasts three universities, two of which have sponsored our congress. Our region, rich in history at the centre of the ancient empire of Charlemagne, has many tourist attractions, which I hope you will be able to enjoy.

Thank you again for coming and I wish you a pleasant stay in France and, in particular, in Lorraine! 


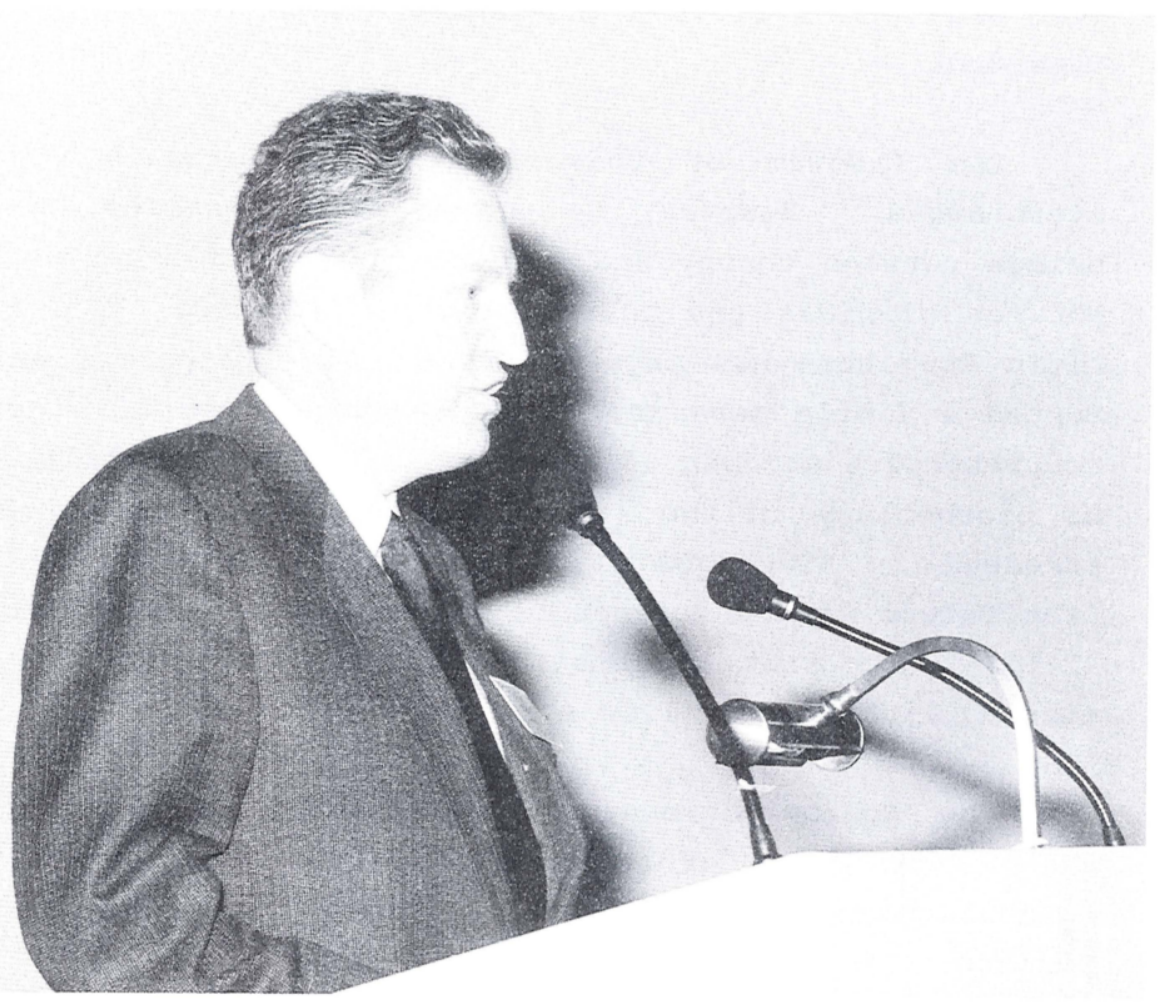

Congress President Jean-François Stoltz, giving his Welcome Address

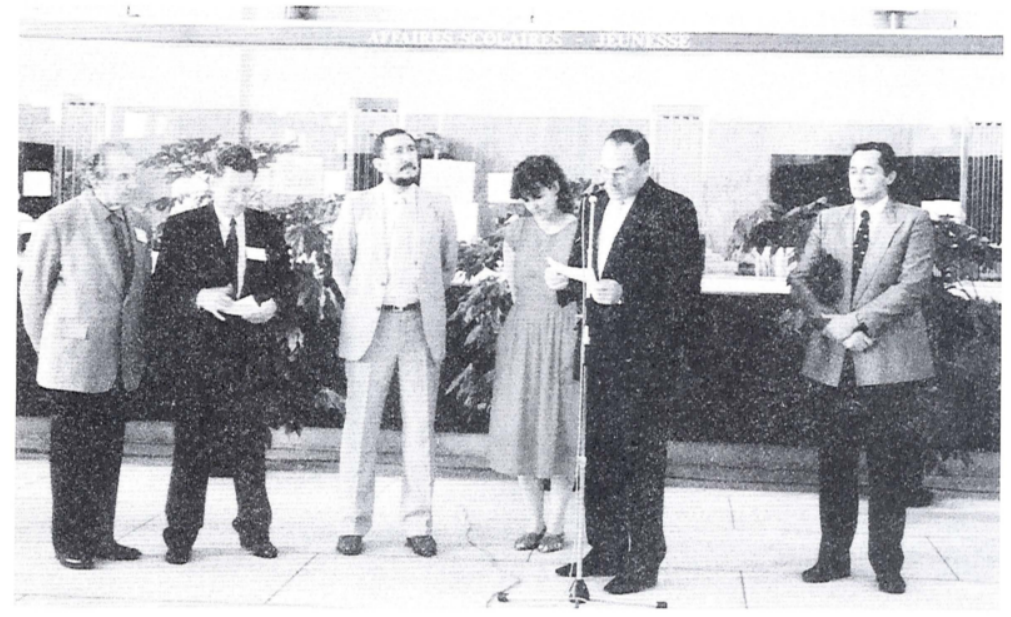

Opening Speakers at the Reception given by the Lord Mayor of Nancy at the City Hall. 